\title{
Carcinoma epidermoide sobre sinus pilonidal
}

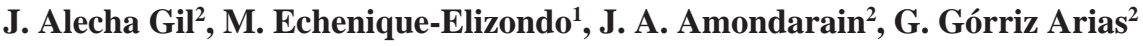

\section{Resumen}

Introducción: La degeneración maligna es una complicación rara observada principalmente en caso de enfermedad pilonidal crónica recurrente y se asocia con un muy mal pronóstico.

Material y métodos: Se han revisado 367 pacientes afectos de quiste pilonidal, bien simple o complicado. Entre ellos hemos encontrado 3 casos $(0,81 \%)$ de carcinoma epidermoide.

Conclusión: El carcinoma epidermoide de sinus pilonidal es una enfermedad infrecuente asociado a un muy mal pronóstico.

Palabras clave:

Sinus pilodinal. Carcinoma escamoso.

Oncología, 2006; 29 (5):227-230

\section{Summary}

Introduction: Malignant degeneration of pilonidal sinus is a rare complication observed mainly in recurrent chronic cases of the disease, associated to a very bad prognosis.

Material and methods: We have reviewed 367 patients with simple and complicated pilonidal cysts. We found 3 cases $(0.81 \%)$ of epidermoid carcinoma.

Conclusions: Pilonidal sinus epidermoid carcino$\mathrm{ma}$ is an infrequent disease predicting for very poor outcome.

Key words: Pilonidal sinus. Epidermoid carcinoma.

${ }^{1}$ Universidad del País Vasco. Departamento de Cirugía. 


\section{Introducción}

El Sinus Pilonidal es una enfermedad muy común, especialmente en hombres, y a menudo complicado por procesos infecciosos locales. Se localiza generalmente en el área sacro-coccígea, pero es descrito también en otras localizaciones tales como ombligo, axila, planta del pie, pene, clítoris y en el canal anal.

La controversia continúa acerca de si éstos quistes pilonidales son congénitos o adquiridos. Los casos asintomáticos se tratan generalmente de forma conservadora, mientras aquellos que son sintomáticos deben ser extirpados quirúrgicamente. Sin embargo, hay una tasa alta de recidiva después de la extirpación quirúrgica a pesar de la técnica utilizada. La degeneración maligna es una complicación rara observada principalmente en caso de enfermedad crónica recurrente y se asocia con un muy mal pronóstico comparado con neoplasias cutáneas de la misma naturaleza. Su tasa de recidiva tras tratamiento quirúrgico es alta. Hasta el presente, solamente 59 casos han sido recogidos en la literatura internacional ${ }^{1}$. Aportamos tres casos nuevos tratados en los Departamento de Cirugía del Hospital Donostia.

\section{Material y métodos}

Hemos recogido los casos de pacientes afectos de carcinoma epidermoide de sinus pilonidal registrados en un Hospital entre enero de 1994 y diciembre de 2004.

\section{Resultados}

Entre enero de 1994 y diciembre de 2004 han sido tratados u total de 367 pacientes afectos de quiste pilonidal, bien simple o complicado. Entre ellos hemos encontrado 3 casos de carcinoma epidermoide $(0,81 \%)$. Las características de cada uno de ellos aparecen reflejados en la Tabla I.

\section{Comentarios-discusión}

La degeneración maligna ocurre en aproximadamente $0,1 \%$ de pacientes con enfermedad pilonidal de evolución crónica no tratada o recidivante ${ }^{2}$. Se cree que es causado por la liberación de radicales libres de oxígeno por células activadas, induciendo la transformación neoplásica por alteraciones genéticas inducidas por los mismos. Adicionalmente, el mecanismo normal de la reparación del ADN se daña en la inflamación crónica y predispone a la degeneración maligna. El primer caso fue descrito por Wolff en 1900 y otros 59 casos adicionales han sido descritos literatura hasta la actualidad ${ }^{1,3}$. El diagnóstico, incluidos nuestros tres casos, se realizó mediante examen y biopsia de una úlceras crónicas con márgenes friables y necróticos, si bien pueden ocurrir como hallazgo casual en examen histológico de un sinus pilonidal extirpado. Las lesiones son los tumores generalmente grandes y con frecuencia más de $5 \mathrm{~cm}$ de diámetro ${ }^{4}$. Las lesiones malignas son profundamente invasivas en el tejido subcutáneo en la gran mayoría de casos. El tejido óseo está afectado en un $8 \%$ de casos ${ }^{4}$.

TABLA I

Descripción de los 3 pacientes

\begin{tabular}{|c|c|c|c|c|c|c|}
\hline & Sexo & Edad & Intervención quirúrgica & Afectación ósea & $Q+R T$ & Seguimiento \\
\hline Caso 1 & V & 54 & $\begin{array}{l}\text { Exéresis "en bloc"+ fascia presacra. } \\
\text { Injerto mallado }\end{array}$ & Sí & $\begin{array}{l}5 \text { x } 5 \text { Gy }(5) \\
5 \text {-FU y leucovorin }\end{array}$ & 12 meses \\
\hline Caso 2 & V & 46 & $\begin{array}{l}\text { Exéresis "en bloc"+ cóccix+colostomia+ } \\
\text { Plastia glútea }\end{array}$ & Sí & No & 4 meses $*$ \\
\hline Caso 3 & $\mathrm{~V}$ & 48 & $\begin{array}{l}\text { Exéresis "en bloc"+ fascia presacra + } \\
\text { linfadenectomía bilateral }\end{array}$ & No & 5-FU y leucovorin & 12 meses * \\
\hline
\end{tabular}

* Fallecido 


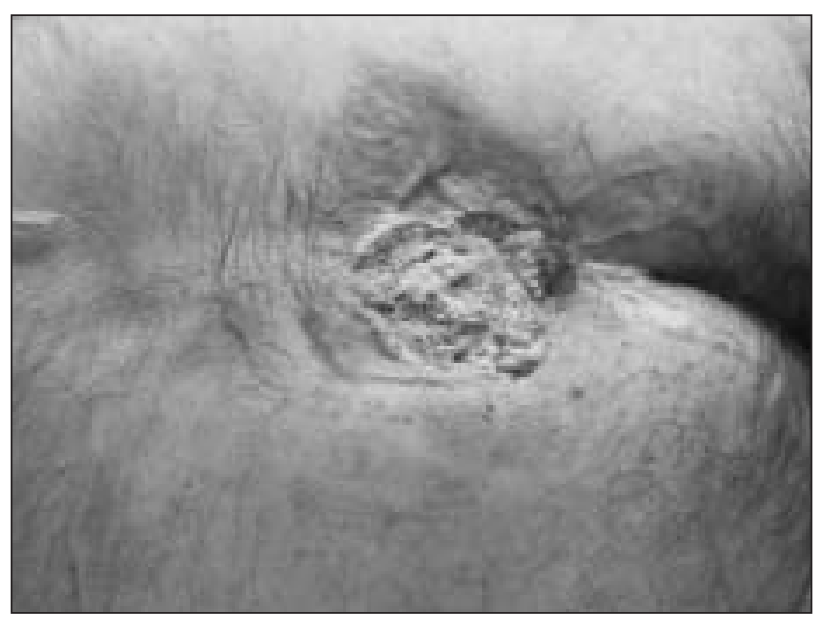

Figura 1. Aspecto clínico. Caso 1.

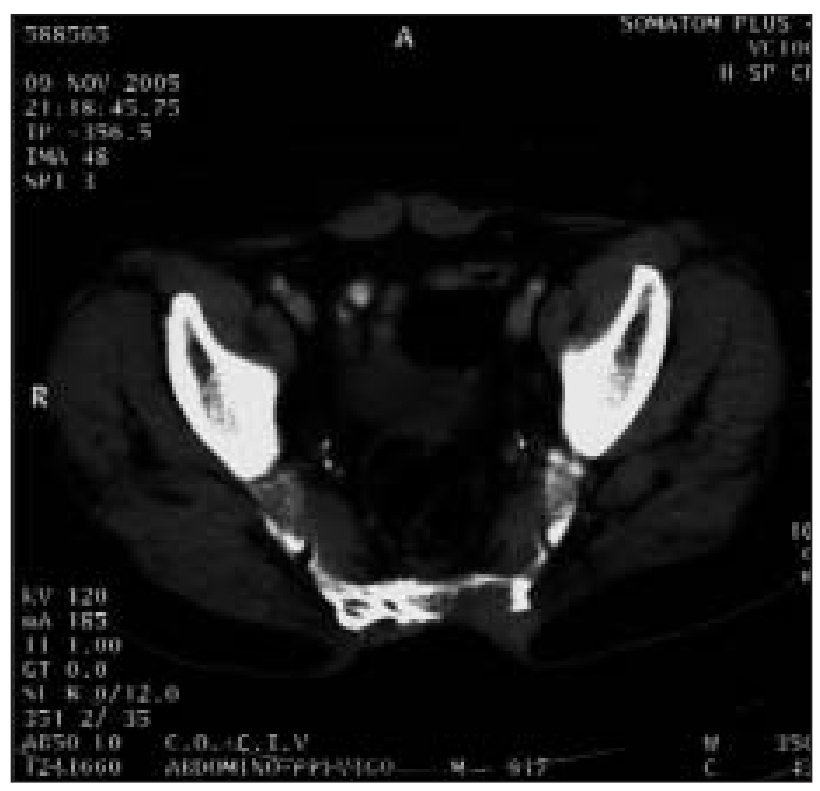

Figura 2. TAC. Caso 1 demostrando invasión del sacro.

Raramente, el diagnóstico se establece tras aspiración con aguja fina de un ganglio inguinal metastático. La rectoscopia puede ser necesaria para excluir la extensión al recto. La tomografía axial computadorizada o la resonancia magnética tienen indicación para demostrar la extensión local y para excluir metástasis intra-abdominales, así como la extensión a ganglios ilíacos y/o para-aórticos ${ }^{2,5}$ y sobre todo en la región inguinal, afectada precozmente.

El tratamiento de la elección debe ser quirúrgico y eliminación en bloque que puede presentar enormes dificultades, porque el tumor es capaz de exten-

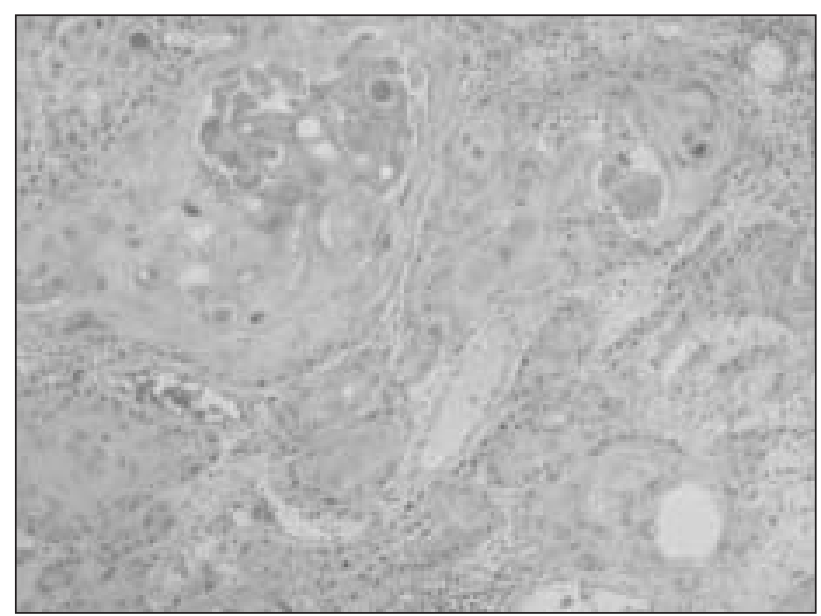

Figura 3. H \& E x 200. Caso 1. Carcinoma epidermoide de bajo grado de malignidad.

derse por los trayectos fistulosos en amplias áreas de las regiones sacro-coccígea y perineal. Esto significa que la exéresis debe incluir incluir por lo menos la fascia presacra, pero a menudo también porciones del sacro, cóccix y recto. El cierre del defecto que resulta se puede realizar con injertos libres o plastias tipo L-L-L (lambeau en L pour losange), así como plastias utilizando el glúteo o el recto interno-gracilis-2, 4, 6 . En algunos casos el uso de las mismas es imposible por lo que hay que dejar cicatrizar por segunda intención el defecto resultante o utilizar técnicas más complejas como plastias miocutáneas del recto anterior del abdomen u omentoplastias seguidas por injertos cutáneos ${ }^{7}$. En un caso publicado fue posible cubrir el defecto mediante una plastia mio-cutánea utilizando el dorsal ancho 3. La recidiva local tras cirugía es frecuente (44\%) y la enfermedad recurrente sucede de forma temprana. La combinación de la cirugía radical con radioterapia post o pre-operatoria precoz parece reducir la recidiva $(30 \%)$. No existen datos en cuanto a la secuencia preferible de cirugía y radioterapia si bien parece ser preferible la radioterapia preoperatorio ya que además, evita riesgos en la viabilidad de injertos y plastias. Los resultados de la quimio y radioterapia combinadas son similares a los observados en el carcinoma escamoso anal ${ }^{8}$.

La metástasis linfáticas inguinales son un signo de mal pronóstico y se asocian con tiempos de supervivencia media de sólo 7 meses. La linfadenectomía regional encuentra por ello su indicación ${ }^{7,8}$. Actualmente, sin embargo, la quimio-radioterapia o 
radioterapia quizás sean sólo una opción a considerar, de forma análoga al tratamiento del cáncer anal de células escamosas con linfadenectomía inguinal asociada ${ }^{9}$. Sin embargo, aunque la quimio-radioterapìa sea el tratamiento primario en el cáncer anal localmente avanzado ${ }^{10}$, la aplicación de la misma en el cáncer de seno de pilonidal no está suficientemente contrastada ${ }^{4,7}$. Ya que el paciente ha de ser intervenido de todas formas es conveniente asociar una linfadenectomía inguinal en todos los casos de diagnóstico preoperatorio claro. El "maping” linfático con biopsia de ganglio centinela para identificar metástasis precoces no parecen práctico. La conducta biológica de carcinoma del seno pilonidal mucho más agresiva que la que ofrece el carcinoma escamoso de otras localizaciones. Por lo tanto, el conocimiento de la posibilidad de degeneración maligna en la enfermedad de pilonidal es esencial para el reconocimiento y el tratamiento tempranos y para la mejora subsiguiente del pronóstico. La información adecuada acerca de la extensión de loco-regional de la enfermedad debe llevar a la planificación y el abordaje óptimos del procedimiento quirúrgico.

\author{
Correspondencia \\ Dr. M. Echenique-Elizondo \\ Catedrático de Cirugía \\ Universidad del País Vasco \\ Departamento de Cirugía \\ UD de Medicina \\ P. Dr. Begiristain, 105 \\ E-20014 San Sebastián (Guipúzcoa) \\ gepecelm@sc.ehu.es
}

\section{Bibiliografía}

1. de Bree E, Zoetmulder FA, Christodoulakis M, Aleman BM, Tsiftsis DD. Treatment of malignancy arising in pilonidal disease. Ann Surg Oncol. 2001 Jan-Feb;8(1):60-4.

2. Val-Bernal JF, Azcaretazabal T, Garijo MF. Pilonidal sinus of the penis. A report of two cases, one of them associated with actinomycosis. J Cutan Pathol 1999; 26: 155-8.

3. Davis KA, Mock CN, Versaci A, Lentrichia P. Malignant degeneration of pilonidal cysts. Am Surg 1994; 60: 200-4.

4. Kulaylat MN, Gong M, Doerr RJ. Multimodality treatment of squamous cell carcinoma complicating pilonidal disease. Am Surg 1996; 62: 922-9.

5. Jeddy TA, Vowles RH, Southam JA. Squamous cell carcinoma in chronic pilonidal disease. Br J Clin Pract 1994; 48: $160-1$.

6. Gur E, Neligan PC, Shafir R, Reznick R, Cohen M, Shpitzer T. Squamous cell carcinoma in perineal inflammatory disease. Ann Plast Surg 1997; 38: 653-7.

7. Abboud B, Ingea H. Recurrent squamous-cell carcinoma arising in sacrococcygeal pilonidal sinus tract: report of a case and review of the literature. Dis Colon Rectum 1999; 42: 525-8.

8. Williamson JD, Silverman JF, Tafra L. Fine-needle aspiration cytology of metastatic squamous-cell carcinoma arising in a pilonidal sinus, with literature review. Diagn Cytopathol 1999; 20: 367-70.

9. Bartelink H, Roelofsen F, Eschwege F, et al. Concomitant radiotherapy and chemotherapy is superior to radiotherapy in the treatment of locally advanced anal cancer: Results of a phase III randomized trial of the European Organization for Research and Treatment of Cancer Radiotherapy and Gastrointestinal Cooperative Groups. J Clin Oncol 1997; 15: 2040-9.

10. Cohen AM, Wong WD. Anal squamous cell cancer nodal metastases: prognostic significance and therapeutic considerations. Surg Oncol Clin N Am 1996; 5: 203-10. 